\title{
PERANCANGAN e-HUMAN RESOURCE MANAGEMENT BERBASIS WEB PADA PT. STD
}

\author{
Agus Budiyantara \\ Teknik Informatika, STMIK WIDURI \\ Email: agusbudiyantara@yahoo.co.id \\ Joni Suhartono \\ Sistem Informasi, School of Information Systems, Universitas Bina Nusantara \\ Jln. K.H. Syahdan No.9, Palmerah, Jakarta Barat 11480 \\ Email: Jonis@binus.edu
}

\begin{abstract}
ABSTRAKSI
Tujuan pembuatan sistem e-HRM ini adalah untuk mengelola kegiatan operasional yang ada pada bagian human resources management mulai dari aktifitas perekrutan, cuti, lembur, mutasi hingga pemutusan hubungan kerja. Metodologi yang di gunakan dalam penulisan penelitian ini meliputi studi pustaka, survei lapangan, serta analisis dan perancangan. Analisis dilakukan dengan cara mewawancarai kepala bagian HRD pada PT. STD untuk mengetahui permasalahan yang terjadi pada unit HRD seperti lamanya proses perekrutan, sulitnya proses cuti maupun sulitnya proses pemutusan hubungan kerja karena datanya tersimpan di beberapa file. Simpulan yang diperoleh dari hasil wawancara menunjukan bahwa penggunaan sistem e-HRM ini dapat membantu unit HRD untuk menyelesaikan masalah yang ada di perusahaan tersebut.
\end{abstract}

Kata Kunci : e-hrm, sumber daya manusia 


\section{PENDAHULUAN}

Manajemen Sumberdaya Manusia merupakan salahsatu bidang dari manajemen umum yang meliputi segi - segi perencanaan, pengorganisasian, pelaksanaan dalam pengendalian. Proses ini terdapat dalam fungsi atau bidang produksi, pemasaran, keuangan, maupun kepegawaian. Karena sumberdaya manusia dianggap semakin penting perannya dalam pencapaian tujuan perusahaan, maka berbagai pengalaman dan hasil penelitian dalam bidang HR dikumpulkan secara sistematis dalam apa yang disebut manajemen sumber daya manusia. Istilah manajemen juga mempunyai arti sebagai kumpulan pengetahuan tentang bagaimana memanage(mengelola) sumber daya manusia (Rivai \& Jauvani, 2010).

Informasi yang dibutuhkan dan hal yang perlu diperhatikan dalam manajemen sumber daya manusia adalah tingkat keterampilan karyawan, kemampuan karyawan, dan kapabilitas manajemen dalam keterkaitannya dengan perencanaan strategi sumber daya manusia. Dengan mengetahui tingkat keterampilan dan kemampuan karyawan, maka perusahaan dapat menentukan arah strategi sumber daya manusia. Tiga konsep utama dalam strategi sumber daya manusia yang mencakup pada keunggulan kompetitif, kapabilitas khusus, dan kesesuaian strategi. Konsep tersebut harus benarbenar diperhatikan agar strategi yang dipilih atau ditetapkan oleh suatu perusahaan dapat berjalan dengan efektif (Cahayani, 2005).

Sampai saat ini masih banyak perusahaan perusahaan, khususnya di Indonesia, yang masih mengalami beberapa masalah terkait pengelolaan HR. Permasalahan tersebut biasanya disebabkan oleh banyaknya dan beragamnya data terkait HR yangmengakibatkan pengelolaan dan proses analisa data HR menjadi tidak efektif dan tidak efisien. Tantangan terbesar dirasakan oleh perusahaan baru yang masih dalam proses perkembangan bisnisnya. Trulsson (2002) mengatakan bahwa data terkait HR yang sangat perlu untuk dikelola adalah terkait skill dan komitmen pegawai yang telah bekerja di perusahaan yang dimaksud. Data ini sangat penting karena hasil analisa dari current employees akan mengarahkan perusahaan pada bagaimana perusahaan harus mengelola pegawai baru yang akan masuk serta bagaimana meningkatkan kemampuan pegawai yang dimilikinya saat ini. Hal ini juga sesuai dengan paparan Bose (2011) bahwa kualitas suatu perusahaan berangkat dari "People Orientation Strategies".

Semakin besar suatu perusahaan, maka semakin banyak dan kompleks pula data sumber daya manusia yang harus dikelola (Kepner \& Tregoe, 2015). Di lain sisi, keputusan yang cepat dan tepat sangat diperlukan oleh para pimpinan perusahaan dalam pengelolaan HR di perusahaannya. Pada titik inilah dibutuhkan suatu integrasi antara ilmu manajemen HR dan managemen TI (Teknologi Informasi) sehingga operasional divisi manajemen HR dapat berjalan secara efektif dan efisien. Keberadaan TI dapat membantu perusahaan dalam memecahkan masalah, diantaranya adalah

membantu manusia dalam meningkatkan produktivitas, meningkatkan efektivitas, meningkatkan efisiensi, meningkatkan mutu, meningkatkan kreativitas, dan problem solving(pemecahan masalah) (Achmad Sirajuddin, Peran Teknologi Informasi dalam Dunia Bisnis).

Salah satu perusahaan yang saat ini sedang dalam proses perkembangan bisnisnya adalah PT.STD.Perusahaan ini berdiri pada tahun 1987 dan bergerak dalam bidang industri tinta. Saat ini,PT.STD a memiliki kurang lebih 130 karyawan dan PT. STD sedang berfokus pada kualitas HR yang bekerja di perusahaan mereka.Dengan pemahaman betapa pentingnya penerapan integrasi manajemen IT dan manajemen HR dalam meningkatkan efisiensi dan efektivitas pengambilan keputusan terkait HR perusahaan ini, penulis terdorong untuk melakukan suatu penelitian mengenai berbagai persoalan yang sering muncul dalam tata kelola HR di PT.STD serta memberikan solusi efektif yang tertuang dalam penelitian yang berjudul "Perancangan e-HRM pada PT.STD”.

\section{Ruang Lingkup}

- Perekrutan calon karyawan hingga menjadi karyawan tetap

- Permintaan Cuti (Cuti kerja, cuti melahirkan, cuti menikah) dan lembur

- Penilaian kinerja karyawan

- Pengunduran dan mutasi karyawan

Tujuan dan Manfaat

Tujuan penelitian :

- Melakukan analisa terhadap proses HRM yang berjalan 
- Merancang sistem e-HRM untuk memudahkan proses bisnis HRM.

Manfaat yang diperoleh adalah :

- Memudahkan staf HRD dalam mengelola proses perekrutan, dan penempatan karyawan

- Memudahkan unit departemen dalam mengelola permintaan karyawan, penilaian karyawan, persetujuan lembur/cuti, mutasi/pemberhentian karyawan

\section{METODOLOGI PENELITIAN}

Metode penelitian yang dilakukan adalah sebagai berikut :

\section{a. Metode Pengumpulan Data}

- Metode Observasi

Kegiatan observasi dilakukan dengan melihat langsung kegiatan HRD yang berjalan pada kegiatan absensi, ijin cuti/lembur.

- Metode Wawancara

Kegiatan wawancara dilakukan ke staf HRD dengan menanyakan bagaimana kegiatan sehari-hari dari proses rekrutment, permintaan ijin cuti/lembur, persetujuan ijin, penilaian, mutasi karyawan. Selain itu kegiatan wawancara juga dilakukan untuk menggali permasalahan yang terjadi pada proses HRD selama ini dan kebutuhan mereka terhadap system informasi

- Metode Studi Pustaka

Studi pustaka dilakukan dengan membaca teori-teori dari bahan pustaka sebagai referensi dalam penyusunan penelitian seperti proses HRD, model penilaian HRD maupun dari sisi perancangan sistemnya.

\section{b. Metode Perancangan}

Metode perancangan yang yang dilakukan adalah System Development Life Cycle dengan membuat diagram-diagram untuk merancang proses, merancang model data, dan merancang tampilan layar

\section{HASIL PEMBAHASAN}

Pada proses bisnis yang sedang berjalan, kami menganalisis proses yang terdapat dalam HRD. Dimana HRD disini melingkupi bagian absensi, rekrutmen. Perekrutan dilakukan jika ada permintaan penambahan tenaga kerja dari manajer divisi. Untuk pekerja lapangan biasa di lakukan dengan pengumuman di bursa tenaga kerja dekat lokasi. Untuk pekerja kantor dilakukan melalui portal job di internet. Proses yang di lakukan memakan waktu kurang lebih satu minggu.

Pada proses abensi, Perusahaan mencatat waktu kehadiran karyawan sebagai catatan untuk penilaian kinerja,jam lembur, jatah cuti dan mutasi karyawan. Teori

\section{Manajemen Sumber Daya Manusia}

Menurut Bohlander \& Snell (2010:4), Manajemen sumber daya manusia merupakan proses dalam mengelola kemampuan manusia untuk mencapai tujuan perusahaan. Keterampilan karyawan, pengetahuan dan kemampuan adalah salah satu sumber daya yang paling khas dan selalu baru. Segala aspek yang mempengaruhi sumber daya manusia di kelompokkan menjadi dua bagian, yaitu competitive challenges (globalisasi, teknologi, pengelolaan perubahan, human capital, tanggap \& pengendalian biaya) dan employee concerns (perbedaan latar belakang, age distribution, gender, keamanan pekerjaan, tingkat pendidikan, hak karyawan, privacy issues, perilaku kerja dan family concerns). Sedangkan menurut Hoon (2002:4), Manajemen sumber daya manusia adalah suatu fungsi yang menunjukkan sesuatu didalam perusahaan yang memberikan fasilitas secara efektif untuk digunakan dalam mencapai tujuan organisasi. Dari beberapa definisi diatas, maka dapat ditarik kesimpulan bahwa manajemen sumber daya manusia adalah suatu fungsi dari organisasi yang terdiri dari proes dan sistem yang dapat mempengaruhi kepegawaian agar dapat berjalan secara efektif sehingga tujuan dari individu karyawan dan organisasi keseluruhan dapat tercapai.

\section{Fungsi Manajemen Sumber Daya Manusia}

Fungsi-fungsi dari manajemen sumber daya manusia adalah sebagai berikut:

\section{Rekrutmen}

Merupakan pengembangan kumpulan calon tenaga kerja yang berhubungan dengan rencana sumber daya manusia (Stoner, Freeman \& Gilbert 2005:71). Adapun tujuan dari rekrutmen adalah menyediakan kelompok calon tenaga kerja yang cukup banyak agar manajer dapat memilih karyawan yang memiliki kriteria sesuai kualifikasi yang mereka perlukan. Menurut Stewart \& Brown (2011:160) 
merekrut karyawan adalah proses mengidentifikasi dan menarik orang-orang untuk bekerja dalam sebuah organisasi”. Sedangkan menurut Snell \& Bohlander (2010:188), rekrutmen adalah proses mencari individu yang mungkin potensial untuk bergabung dengan organisasi dan mendorong mereka untuk melamar lowongan pekerjaan yang ada atau yang diantisipasi.

\section{Seleksi}

Menurut Stewart \& Brown (2011:45), seleksi adalah proses dimana instrument tertentu terlibat untuk memilih dari kolam individu yang paling cocok untuk pekerjaan yang tersedia. Beberapa prinsip yang harus dterapkan dalam menjalankan metode seleksi yaitu reliability, validity, utility, fairness, and acceptability .Sedangkan menurut Snell \& Bohlander (2010, p.254) menerangkan bahwa seleksi adalah proses memilih individu yang memiliki kualifikasi yang relevan untuk mengisi lowongan pekerjaan yang ada atau yang diproyeksikan. Menurut Mondy (2010:158), Seleksi adalah proses memilih individu dari sekelompok pelamar yang paling cocok untuk posisi tertentu disuatu organisasi.

Bohlander \& Snell (2010:254) menerangkan bahwa seleksi adalah proses memilih individu yang memiliki kualifikasi yang relevan untuk mengisi lowongan pekerjaan yang ada atau yang di proyeksikan. Sebuah proses seleksi yang baik adalah salah satu yang direncanakan dengan baik dan dioperasikan dengan baik. (Mustapha, Ilesanmi,

\& Aremu, 2013). Langkah - langkah dalam proses seleksi antara lain:

- Melengkapi lamaran pekerjaan •

Mengikuti tes

- Penyelidikan latar belakang •

Wawancara seleksi

- Menawarkan pekerjaan

- Performance Appraisal

Merupakan suatu proses menyampaikan informasi secara terus menerus kepada bawahan mengenai prestasi kerja mereka yaitu untuk memberikan umpan balik kepada karyawan, berupa informasi seberapa baik mereka melakukan pekerjaannya untuk organisasi atau perusahaan (Stoner, Freeman \& Gilbert 2005: 87). Byars \& Rue (2006:223) mengungkapkan bahwa penilaian kinerja adalah proses mengevaluasi dan mengomunikasikan bagaimana karyawan melaukan pekerjaan dan menyusun rencana pengembangan kepada para karyawan itu sendiri. Saat dilakukan secara tepat, penilaian kinerja tidak hanya memungkinkan karywan mengetahui seberapa baik kinerja yang mereka miliki tetapi juga mempengaruhi tingkat usaha dan arahan tugas mereka dimasa depan.

Proses :

1. Calon Karyawan menyerahkan CV

2. Setelah Calon Karyawan menyerahkan CV, Staff

HR mengecek CV Pelamar

3.Jika sesuai kebutuhan, makan Staff HR akan menginput data dari CV Pelamar

4. Sesudah menginput data Pelamar, Staff HR akan melakukan Penjadwalan Test

pada setiap Pelamar tersebut yang nantinya dapat dilihat oleh Staff HR dan HR Manager

5. Setelah itu, Staff HR melakukan pemanggilan kepada pelamar untuk melakukan test

6. Calon Karyawan yang telah mendapatkan panggilan akan melakukan test

7. Calon karyawan yang telah melakukan test, hasilnya akan di setujui oleh HR Manager

8. Jika disetujui, data Calon Karyawan tersebut akan di update oleh Staff HR menjadi Karyawan Kontrak

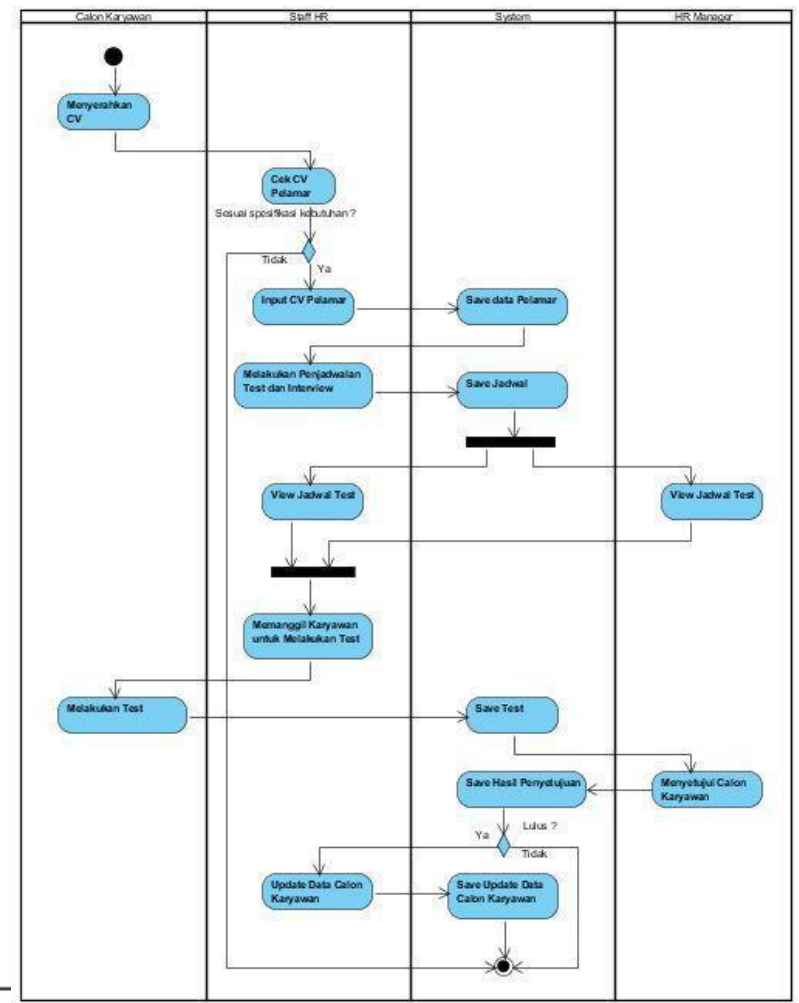


Gambar 1 Activity Diagram Rekrutment

Activity Diagram Penilaian Kinerja

Proses :

1. Manager Divisi menyerahkan komponenkomponen penilaian untuk diinput oleh StaffHR

2. StaffHR menginput Komponen-Komponen KPI

3. Setelah melakukan input komponen KPI, Manager Divisi dapat melakukan input hasil Penilaian Kinerja

4. Hasil Penilaian tersebut dapat dilihat oleh Staff HR, Manager Divisi dan HR Manager

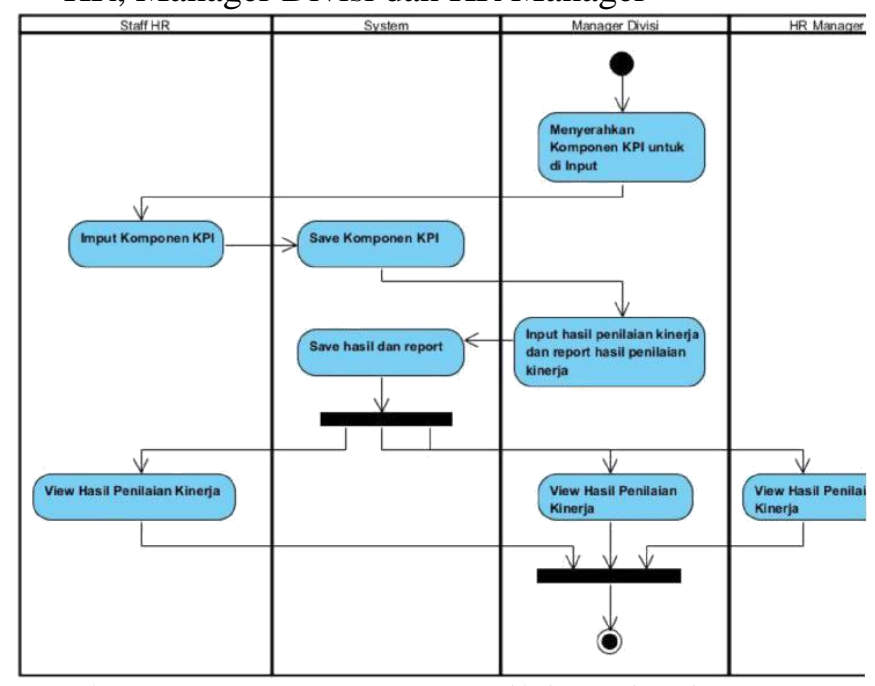

Gambar 2 Activity Diagram Penilaian Kinerja

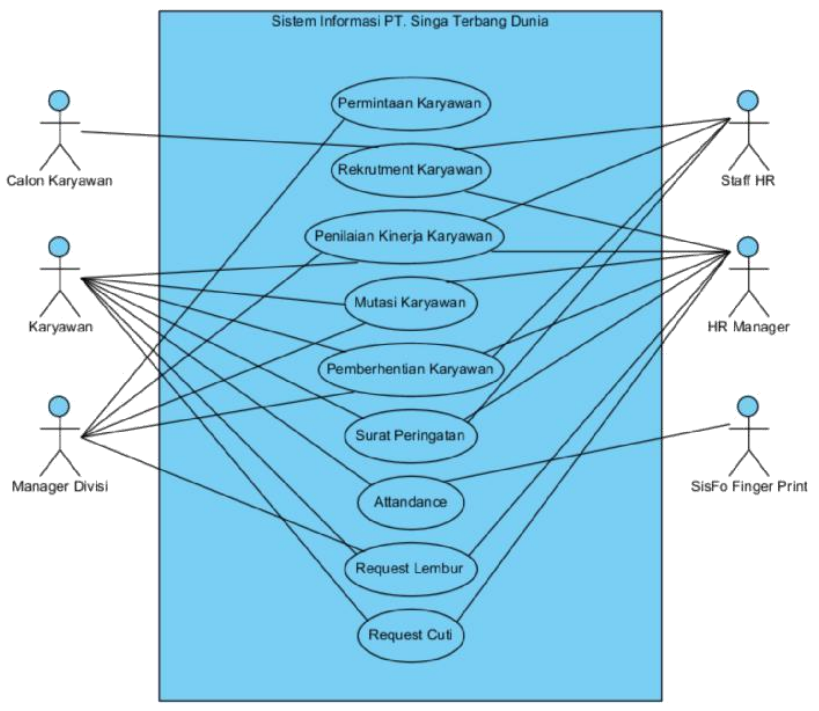

Gambar 3 Use Case Diagram e-HRM

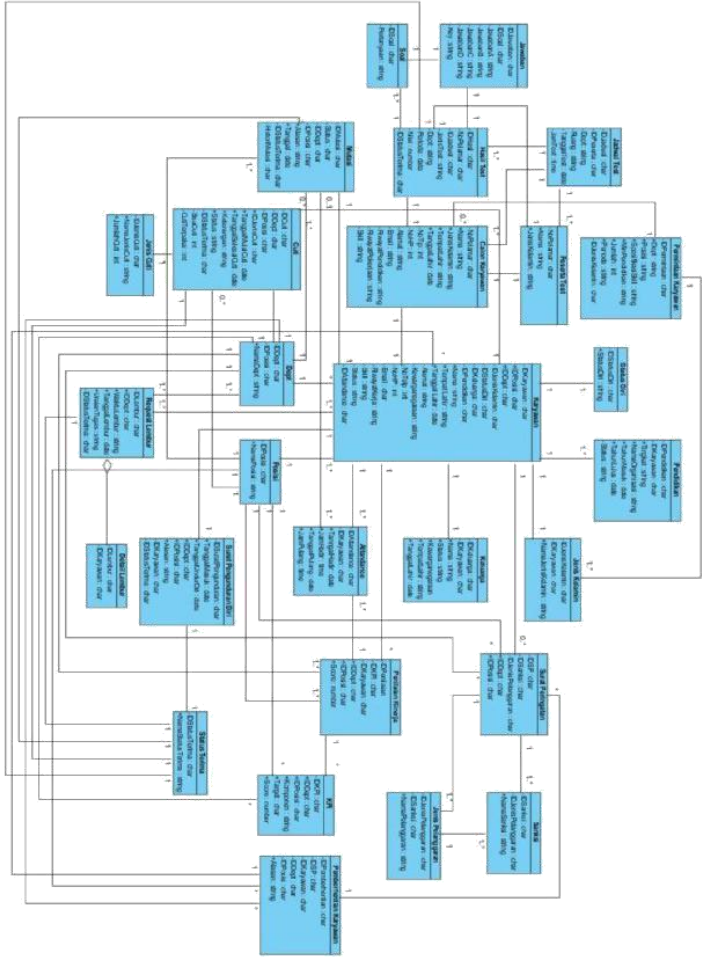

Gambar 4 Class Diagram

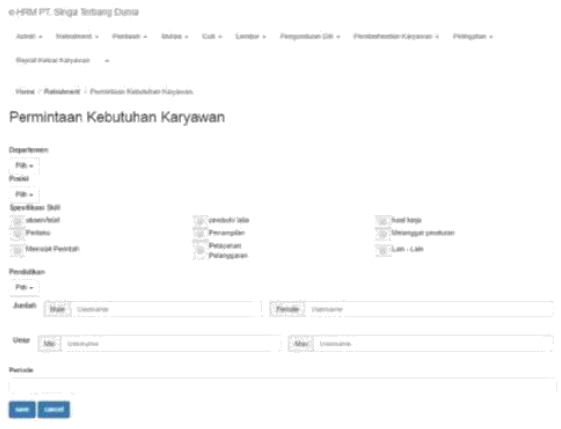

Gambar 5 Tampilan layar input kebutuhan karyawan

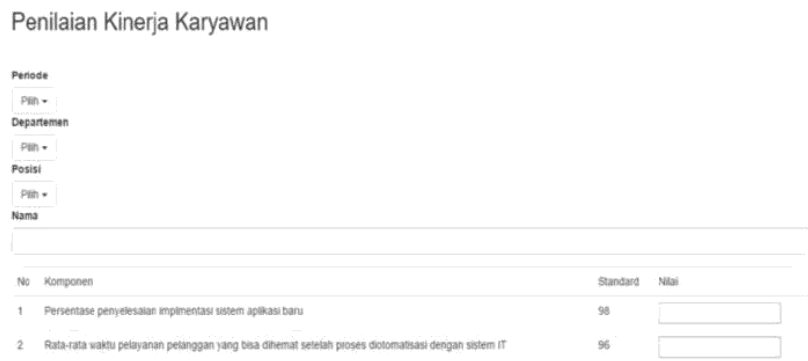

sine

Gambar 6 tampilan layar input penilaian kinerja 


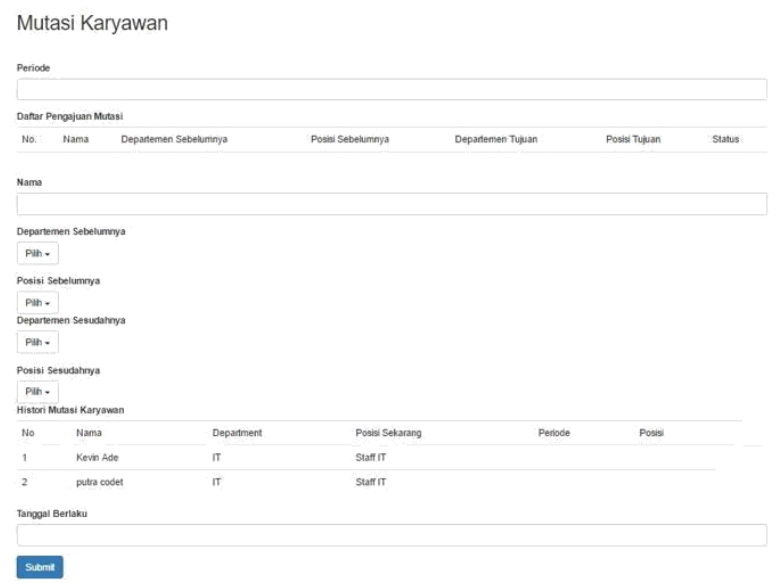

Gambar 7 tampilan layar Input mutasi

\section{SIMPULAN}

Berdasarkan hasil analisis sistem dan pembahasan yang telah disampaikan pada bab bab sebelumnya, maka dapat di ambil kesimpulan sebagai berikut :

Tata kelola HR yang ada di PT.STD tersebut meliputi proses perekrutan karyawan, mutasi karyawan, penilaian karyawan pemberhentian atau pengunduran diri karyawan, pengajuan cuti, pengajuan lembur, dan absensi.

Dengan adanya perancangan e-Human Resource Management yang akurat dapat menyelesaikan berbagai permasalahan terkait data HR yaitu HR dapat mudah dalam mengelola data karyawan seperti dalam melakukan proses perekrutan karyawan, dalam memilih calon pelamar yang masuk untuk dilakukan proses lebih lanjut karena data pelamar dapat langsung dilihat semua dan juga membantu HR dalam memantau permintaan kebutuhan tenaga kerja per divisi ketika terjadinya kekurangan karyawan pada perusahaan, untuk riwayat laporan HR dapat dengan mudah mencari data riwayat - riwayat seperti jatah ijin cuti yang masing - masing berbeda di setiap jenis cutinya, dan riwayat data karyawan yang lembur untuk keperluan penghitungan gaji.

\section{REFERENSI}

Aprianto, Brian \& Jacob, Fonny, Arisandy.(2013).Pedoman Lengkap Profesional SDM Indonesia (HC). Jakarta : PPM
Bohlander, George., \& Snell, Scott. (2010). Principles of Human Resource Management, 15th ed. Mason, OH: South Western - Cengage Learning

Bose. (2011). Hold People Accountable for Results. TKO Management!, 91-101.

Byars, L. L., \& Rue, L. W. (2006). Human Resource Management, 8th Edition. New York: McGraw-Hill.

Cahayani, Ati. (2005). Strategi \& Kebijakan Manajemen Sumber Daya Manusia.Jakarta : PT. Indeks.

David, Parmenter.(2007). Key Performance Indikators. Jakarta : PT Elex Media Komputindo

Ivancevich, J. M., \& Hoon, L.S. (2002). Human Resource Management in Asia. Singapore : Mc Graw-Hill Education (Asia).

Kepner, H. C., \& Tregoe, B. B. (2015). The Rational Manager. Journal of Marketing, 30(1).

Mustapha, M. A., Ilesanmi, O. A., \& Aremu, M. (2013). The Impact of Well Planner Recruitment \& Selection Process on Corporate Performance in Nigerian Banking Industry. International Journal of Academic Research in Business \& Social Science, 3.

Mondy, R. Wayne. (2010).Human Resource Management Eleventh Edition. New Jersey: Prentice Hall

Mathis Robert L. \& Jackson John H.(2006).Human Resource Management, alih bahasa. Salemba Empat. Jakarta.

Noe, Raymond A., \& Liu, X. (2010). Human Resource Management, Gaining Competitive Advantage 3rd Edition. McGraw-Hill.

O'Brien, James A. (2005). Pengantar Sistem Informasi : Persefektif Bisnis \& Manajerial. (12th edition). Salemba edition. Salemba Empat, Jakarta.

Romney, Marshall B., \& Steinbart, Paul J. (2006). Accounting Information Systems.(10th ed). Pearson Prentice Hall, New Jersey. 
Rivai, V., \& Jauvani, E. (2010). Manajemen Sumber Daya Manusia untuk Perusahaan. Jakarta: PT.Raja Grafindo Persada.

Rahmana, A. (2009). Peranan Teknologi Informasi Dalam Peningkatan Daya Saing Usaha Kecil Menengah. Seminar Nasional Aplikasi Teknologi Informasi.

Satzinger, J. W., Jackson, R. B., \& Burd, S. D. (2012). Systems Analysis \& Design:

In a Changing World (6th ed.). Boston: Course Technology : CENGAGE Learning.

Stoner, J.A.F., Freeman, R.E., \& Gilbert, D.R. (2005). Management Edisi ke- 13.New Jersey : Prentice Hall Uma

Stewart, G. L., \& Brown, K. G. (2011). Human

Resource Management: Linking Strategy to Practice,2nd Edition. United States of America: John Wiley \& Sons, Inc.

Trulsson. (2002). Aligning Human Resources and Business Strategy. Journal of Research Management and Business Strategy, 48-59. 
